\title{
LA LEGITIMACIÓN EN LA ERA DE LA POSTMODERNIDAD
}

1

En un trabajo sobre la obra de Hume que ya puede considerarse clásico, se sitúa la siguiente reflexión de Deleuze: «Aquí encontramos el principio de toda filosofía política seria. La verdadera moral no se dirige a los niños en el seno de la familia, sino a los adultos en el seno del Estado. No consiste en cambiar la naturaleza humana, sino en inventar condiciones artificiales objetivas tales, que los malos aspectos de esta naturaleza no puedan triunfar». Y añade a continuación el autor: «Se trata de una invención que ha de ser, tanto para Hume como para todo el siglo XVIII, política y nada más que política» ${ }^{1}$.

Ahora cabe preguntarnos por la fortuna de esta reflexión en los siglos posteriores, esto es, especialmente, en qué medida el mundo moderno, representado bajo este aspecto por las afirmaciones que acaban de recogerse, de evidente inspiración ilustrada, ha sufrido el «asalto», primero del modernismo y luego de la posmodernidad. ¿En qué ha quedado, en otras palabras, el punto de partida de Hume? La pregunta es pertinente en la medida en que en la obra del pensador escocés se pueden encontrar rasgos que, en principio, y pendientes de una calificación posterior más precisa, son asignables, tanto a una legitimación moderna como también a una que llamaremos, provisionalmente, posmoderna.

En efecto, en la obra de Hume, especialmente en su obra política, encontramos elementos que permiten una explicación y justificación de la vida social, económica y política, de distinto signo. Así, por una parte, la filosofía política gira en tomo a tres ejes relativos a la diversidad de los intereses y a su recíproca composición. El punto de partida está constituido por la extensión, diferenciación y generalización de intereses, circunstancia que hace inestables a estos. Como

${ }^{1}$ G. Deleuze, Empirismo y subjetividad. Trad. cast. H. Acevedo, Ed. Gedisa, Barcelona, 1981, págs. 47-48. 
consecuencia, el interés general resulta variable y conflictivo. La necesaria estabilización del mismo, choca, sin embargo, con inconvenientes como la escasez de bienes o la desigualdad generada por la propiedad ${ }^{2}$. Finalmente, la introducción de la economía política, como conjunto de reglas susceptible de recomponer tanto la desigualdad cuanto la escasez, mediante la prosperidad a que conduce el comercio (tan artificial, por cierto, como la legislación, el Gobierno o la propia justicia), al incrementar la actividad de los individuos y no permitir que nadie perezca o se vuelva inútil ${ }^{3}$.

No es sorprendente encontrar este tipo de elementos en la obra de Hume. Como es sabido, constituye una constante en todo el pensamiento ilustrado, y en especial en la tradición inglesa, la idea, desarrollada en dos niveles, de un espacio de intereses conflictivos y de un espacio político ordenador de los mismos a través de un marco regulativo. Tanto el Gobierno, con su legislación acerca de la propiedad, como la economía política, resultan mecanismos correctores de la escasez de bienes y del enfrentamiento de intereses. En efecto, es el progreso del comercio el que corrige la tensión riqueza-pobreza con la inevitable aplicación de las reglas de la oferta y la demanda, del mismo modo que los impuestos se presentan como justa reclamación del Estado de una parte del capital acumulado por la propiedad del comercio ${ }^{4}$. De esta manera se anuncia ya la racionalización calculadora y utilitaria que caracterizará al Estado moderno, y con ello también, los fundamentos de una legitimación legalista y formal.

Pero, por otra parte, encontramos también en Hume elementos que pueden situarse más allá de la tradición ilustrada, demostrando en ellos una sorprendente anticipación de lo que, sobre todo en el campo político y jurídico, pueden considerarse enfoques y puntos de vista dialógicos, introductores de la razonabilidad y, si se me permite la expresión, la procedimentalidad. No hay que olvidar, en este sentido que para Hume, las reglas de la cultura, y por tanto, las reglas del Derecho y de la política, se determinan por la asociación y la fantasía, en cuanto afección pasional de la imaginación. Pues son precisamente las reglas de la asociación las que determinan las reglas de la propiedad (como ocupación, accesión, sucesión y prescripción), teniendo como principio de la asociación la «transición fácil». En un

${ }^{2}$ D. Hume, A Treatise of Human Nature, en Philosophical Works in 4 vols. (Ed. London 1886), Scientia Verlag. Aalen, 1964, vol. 2, pág. 258. An Enquiry Concerning the Principles of Morals, Vol. 4, pág. 197.

${ }^{3}$ Political Discourses. En especial, Of Commerce, en ob. cit., Vol. 3, págs. 296 y ss. e Idea of a Perfect Commonwealth, en ob. cit., Vol. 3, págs. 480 y ss.

${ }^{4}$ En especial, Of Interest, en ob. cit., Vol. 3, págs. 232 y ss. y Of Taxes, también en Vol. 3, págs. 356 y ss. 
conocido párrafo de su Tratado de la naturaleza humana, escribe Hume: «Decimos estar en posesión de una cosa no sólo cuando la tocamos directamente, sino también cuando nos hallamos en tal situación respecto a ella que está en nuestro poder el utilizarla, y nos es posible moverla, modificarla o destruirla según el placer o utilidad. Es un tipo de relación de causa a efecto. Como la propiedad no es mas que una posesión estable que proviene de las reglas de la justicia y las convenciones humanas, tiene que ser considerada como de la misma especie de relación. Pero cabe observar que como el poder de utilizar un objeto es más o menos cierto, según que las interrupciones que nos afecten sean más o menos estables, y como esta probabilidad puede incrementarse según grados imperceptibles, en muchos casos no es posible determinar el comienzo y final de la posesión; tampoco existe un criterio de certeza con el que resolver los conflictos [...] ¿Quién señalará los límites precisos entre una y otra y determinará el criterio para resolver todas las disputas que pueden surgir y que, como muestra la experiencia, surgen con frecuencia en este tema?». Y en una importante nota, añade Hume que ni la razón ni el interés público ofrecen solución a estas dificultades, como tampoco la imaginación, pudiéndose encontrar ejemplos no susceptibles de solución, ya que muchos de estos casos no tienen solución posible, en la medida en que «todo el problema depende de la fantasía, que en este caso no posee ningún criterio preciso y determinado para ofrecer una sentencia» ${ }^{5}$.

Encontramos así en el campo jurídico, de la propiedad, el efecto de las asociaciones de ideas y de la «fácil transición» de la imaginación de unas a otras ${ }^{6}$. Nos movemos dentro del ámbito de las pasiones, distinto del ámbito propio del entendimiento, en el que la imaginación libera sus propias formas, ampliándolas y extendiéndolas infinitamente, haciendo de los límites objetos de la fantasía, separando, por ejemplo, el poder de su ejercicio actual. «Al tratar del entendimiento -escribe Hume- se ha señalado que la distinción realizada algunas veces entre un poder y su ejercicio es absolutamente intranscendente, y que no existe hombre ni ser alguno que crea tener capacidad para algo a menos que lo ejerza y lo ponga en acción. Pero aunque esto sea rigurosamente cierto en el pensamiento estricto y filosófico, no es esta la filosofía de nuestras pasiones; al contrario, hay muchas cosas que actúan sobre las pasiones por medio de la idea y suposición del poder, con independencia de su ejercicio real» ${ }^{7}$.

${ }^{5}$ A Treatrise... en ob. cit., vol. 2, págs. 276-277, nota 1 (Subrayado mío).

${ }^{6}$ Ibídem, págs. 281, nota 2.

${ }^{7}$ Ibíd., pág. 108. 
Interesa subrayar aquí que, dadas estas condiciones, el Derecho aparece, en cierto modo, como un campo «asociacionista». En efecto, reclama un juez, un árbitro, que resuelva los conflictos, no tanto según la razón o el público interés (incapaces, como se ha indicado, de ofrecer criterios suficientes), sino más bien según la asociación de ideas, esto es, según una relación entre la cosa objeto de conflicto y el espíritu de un «observador general», lo que supone conferir a la imaginación un carácter casi constituyente. Una última referencia al texto de Hume puede resultar ilustrativa: «... me parece -dice- que estas reglas de la propiedad se encuentran determinadas por la imaginación, por las propiedades más frívolas de nuestro pensamiento y de nuestro poder de concepción» ${ }^{8}$. Podría decirse, en definitiva, que el Derecho no puede fundarse mas que en una buena fe entendida experimentalmente, en el sentido de que la construcción de convenciones responde a su utilidad. No hay otra posibilidad: el ser humano necesita una ordenación de su territorio, un territorio íntimo, y no universal, como será, muy pronto, el territorio del sujeto kantiano.

Las anteriores consideraciones explican la elección de Hume como punto de partida. Una elección que no responde simplemente a motivos históricos o eruditos. Pues a pesar del indudable interés que este autor encierra como antecedente del problema de la legitimación moderna, nos ha permitido, sobre todo, poner de manifiesto la presencia de dos distintas líneas de legitimación, aspecto este que constituye el verdadero punto de partida del trabajo y que, como antes se advirtió, requiere una caracterización más precisa.

2. Estas dos líneas, presentes en la actualidad, pueden asignarse a dos momentos temporales distintos, aunque sucesivos, de los que traen su identificación: legitimación moderna y legitimación posmoderna respectivamente. No resulta fácil distinguir estos dos momentos temporales. Modernidad y posmodernidad son hoy dos conceptos discutidos y polémicos, tanto considerados aisladamente como en su relación. Esta situación se complica, además, si referimos la posmodernidad al ámbito de lo jurídico, pues lo que se entiende por tal en este ámbito no coincide exactamente (o al menos no está clara su correspondencia) con el posmodernismo cultural en general. Veamos.

Es necesario referirse, en primer lugar a la modernidad. Los límites de este trabajo no permiten, sin embargo, un extenso planteamiento de esta cuestión, extensa de por sí, sobre la que existe, por lo demás, abundante literatura9. Ya la propia delimitación del arco

${ }^{8}$ Ibíd, p. 273.

${ }^{9}$ En esta misma línea de brevedad, limitaremos esta relación a unos pocos textos 
de tiempo que comprende la modernidad es problemática, en cuanto que su comienzo es discutido, no siéndolo menos su final, o tal vez mejor, decadencia (esto es, el paso a la posmodernidad, precisamente). Tal vez lo conocido del tema pueda servir de pretexto para dispensarme de entrar en tan complejo asunto y arriesgar una breve caracterización, más bien una noticia, desde luego necesariamente incompleta.

Pues no podemos dejar de recordar, en efecto, algunos conceptos que van indisolublemente unidos a la modernidad. Secularización, progresos en el conocimiento y la ciencia (no sólo de índole material, sino, sobre todo, metodológica), primado de la razón, ilustración, Derecho natural, libertad (tanto personal como económica, de mercado) igualdad (ante la ley, abolición de privilegios y estamentos), propiedad privada, derechos del hombre, Estado de Derecho, Soberanía popular, constitución, parlamento, burocracia, centralización, etc. Probablemente podría aumentarse este catálogo con otras nociones y conceptos. Pero creo que los que se han recogido son suficientes para dar una idea de la profunda transformación que supuso la modernidad, así como de su incidencia sobre los más diferentes ámbitos de la vida social. Se comprende, finalmente, que estos aspectos, verdaderamente revolucionarios, habían de replantear el problema de la legitimación en términos completamente nuevos.

En este sentido, podrían contraponerse, siguiendo a Habermas, una sociedad tradicional y una sociedad moderna, cada una con su correspondiente sistema de legitimación. La primera no se identifica con la sociedad primitiva, separándose de ella por tres notas principales: centralización del poder por el Estado, división en clases socioeconómicas que participan de modo desigual en el producto social y cosmovisión general que explica el orden de la sociedad y el puesto asignado al individuo en dicho orden, legitimando por esta vía el reparto desigual del trabajo y los excedentes. Globalmente, puede decirse que el desarrollo de las fuerzas productivas (subsistema técnico) no ha alcanzado un grado de desarrollo suficiente como para cuestionar la legitimación propuesta por la cosmovisión, manteniéndose por lo tanto, dentro de los límites de la efectividad legitimante de las tradiciones culturales.

Frente a ella, la sociedad moderna se caracteriza por un desarrollo

de distinta orientación: P. Hazard: La crisis de la conciencia europea, trad. cast. J. Marías, Ed. Pegaso, Madrid, 1952 ( $2^{\mathrm{a}}$ ed.); Id.: El pensamiento europeo en el siglo XVIII, trad. cast. J. Marías, Ed. Alianza, Madrid, 1988; P. Messnard: Léssor de la philosophie politique au XVIe siecle, Ed. Vrin, París, 1968 (3 $3^{\mathrm{a}}$ ed.); G. Peces-Barba: Tránsito a la modernidad y derechos fundamentales, Ed. Mezquita, Madrid, 1982. 
sistemático y permanente de las fuerzas productivas. Coincidiendo su comienzo con el surgimiento de la sociedad burguesa, la economía responde a una lógica del desarrollo basada en la acción técnica. Como consecuencia, la técnica se independiza del marco institucional (tradición cultural), dando lugar a un nuevo tipo de racionalidad, la racionalidad técnica, que rompe la fuerza y la validez de la interpretación cosmológica, cayendo al mismo tiempo la interpretación de la sociedad. De este modo, el subsistema técnico, en la terminología de Habermas, se introduce en los sectores de la vida humana antes dominados por la acción comunicativa (esto es, una interacción mediada por símbolos y regida por normas cuya validez deriva de su reconocimiento por los sujetos actuantes, que definen esperanzas recíprocas de comportamiento que han de ser reconocidas por los sujetos actuantes). Así, tanto la división del trabajo y el reparto desigual, como la propia desigualdad política pierden legitimación ${ }^{10}$.

Nos encontramos, pues, ante la sustitución de la religión y de la metafísica por la ciencia, verdadera seña de identidad de la modernidad. En puridad, se inaugura un momento histórico a partir del cual no podía seguirse reconociendo la desigualdad y la opresión. Pero es sabido que estas esperanzas se vieron muy pronto defraudadas. «La crítica del cielo» debía convertirse, en palabras de Marx, en «crítica de la tierra». En efecto, el mantenimiento del reparto desigual del trabajo y de los excedentes sociales exige una nueva línea de legitimación que la sociedad burguesa sitúa en la propia forma de producción y de racionalidad técnica que la acompaña.

Llegados a este punto no puede evitarse la alusión a Weber, una vez más ${ }^{11}$. Weber habla de legitimación desde dos ángulos confluyentes. Desde el primero de ellos, la orientación de la acción social por un orden puede tener lugar porque dicho orden aparezca como obligatorio y modélico para los actores, advirtiendo Weber que un orden sostenido con el prestigio de la legitimidad resulta más sólido que el sostenido por otros motivos, pudiendo los actores atribuir legitimidad por tradición, creencias emotivas o racionales (Derecho natural), o por legalidad, como obediencia a preceptos jurídicos positivos establecidos según un procedimiento determinado y formalmente

${ }^{10} \mathrm{~J}$. Habermas, Ciencia y técnica como ideología, trad. cast. M. Jiménez Redondo y M. Garrido, Ed. Tecnos, Madrid, 1986, págs. 65-66. También del mismo: La reconstrucción del materialismo histórico, trad. cast. J. Nicolás y R. García Cotarelo, Ed. Taurus, Madrid, 1985, p. 273.

${ }^{11}$ Si bien Elías Díaz advierte de lo reiterativo de la reproducción de los textos de Weber (De la maldad estatal a la soberanía popular, Ed. Debate, Madrid, 1984, p. 10) considero inevitable esta alusión, aún disculpándome por ello y con la intención de que sea de la brevedad más imprescindible. 
correcto $^{12}$. Desde el segundo ángulo, parte de la dominación, considerando como elemento definitorio de la misma la probabilidad de obediencia, que supone la existencia de un cuadro administrativo igualmente ligado a la obediencia por motivos entre los que destacan una racionalidad con arreglo a fines y una racionalidad con arreglo a valores. Toda dominación, añade Weber, procura rodearse de una creencia relativa a su legitimidad, pudiendo distinguirse tres tipos (ideales) de dominación legítima: tradicional, carismática y racional. Esta última se apoya en la creencia en la legalidad de las ordenaciones estatuidas, y supone una obediencia a los llamados a ejercer la autoridad por esas mismas ordenaciones. Se trata de una legitimidad legal-racional basada en la propia legalidad formal de sus disposiciones, considerada por Weber como la forma específicamente moderna de legitimidad ${ }^{13}$.

La nueva sociedad burguesa, en efecto, había operado con fortuna desigual, en dos campos diferentes: el de la interpretación de la naturaleza, cuyo conocimiento y dominación exigía una actitud técnica, y el campo de la moralidad, en el que, aniquiladas las antiguas formas de legitimidad religiosa y descartada la superación de la injusticia social, no cabía sino la creación de una nueva línea de legitimación. El capitalismo ofrecerá, en este sentido, una legitimación del poder que nace de la base misma del trabajo social. La institución del mercado, en el que los individuos cambian sus mercancías (incluyendo la que consiste en la propia fuerza de trabajo), garantiza la justicia de la equivalencia de las relaciones de intercambio, con lo que la reciprocidad se convierte en principio (objetivo, anónimo) de organización del proceso de producción y reproducción social. El mecanismo del mercado, al introducirse en los sectores de la vida humana antes dominados por lo que Habermas denomina acción comunicativa, produce una paulatina racionalización de los mismos. Así, la propiedad deja de estar incluida entre los elementos que la tradición legítima, pasando a adquirir una legitimación económica. Y en sentido semejante, la burocracia, la educación, la familia, el transporte, etc. ${ }^{14}$

Elías Díaz se pregunta cómo fue posible la relativa implantación social del modelo de legitimación legal-racional en la sociedad ${ }^{15}$.

${ }^{12}$ M. Weber, Economía y sociedad, trad. cast. J. Medina Echevarría, J. Roura, E. Imaz, E. García Máynez y J. Ferrater Mora, Ed. Fondo de Cultura Económica, México, 1984 (2ª ed., $17^{\mathrm{a}}$ reimp.), pp. 25-29.

${ }^{13}$ Ibidem, págs. 170-172.

${ }^{14}$ J. Habermas, La reconstrucción..., cit., pág. 271.

${ }^{15}$ E. Díaz, ob. cit., pág. 49. En este texto, el autor distingue entre legitimidad, que conecta con el sistema de legalidad, y legitimación, conectada con la dimensión social: «La propensión a una positivista sacralización de la legalidad -escribe- 
Una primera respuesta se refiere a la imposición ideológica derivada de intereses reales de la burguesía, en ascenso desde tiempo atrás, que utiliza como argumentos principales, por un lado, el iusnaturalismo racionalista, que concreta muy pronto como legalidad burguesa y liberal, y por otro lado, la concepción de la legalidad como producto de la soberanía popular. Este segundo aspecto, que expresa el potencial crítico de la ilustración política, confirma que en la legalidad burguesa se sitúan diversos contenidos de legitimidad. Así, en principio, esta legitimidad es fruto, no sólo de la libertad, sino también de la seguridad: la introducción de la racionalidad y de las formas jurídicas se entiende, de modo muy principal, como una estrategia frente al peligro de la arbitrariedad y el despotismo. En este sentido, la legitimidad moderna es equivalente también a Estado de Derecho. Pero advierte inmediatamente Elías Díaz, que dicha legitimidad no debe considerarse como exclusivamente formal, pues ello supondría un empobrecimiento de la legitimidad democrática ${ }^{16}$.

Hay pues, siempre según Elías Díaz, un hilo conductor entre legitimidad legal y legitimidad democrática, aunque no una identidad. «En los sistemas democráticos basados en la soberanía popular -escribe- se crean valores derivados de la libertad humana, base ineludible de la soberanía popular [...] que no agotan, o que no pueden agotarse, en modo alguno, en la mera legalidad. Así, la soberanía no es una instancia formal, sino conectada en profundidad con valores básicos, inviolables, como es el valor de la libertad. Precisamente por ello -concluye-, esto es, porque la libertad se sitúa por encima de la legalidad y puede incidir en ella, es posible hoy hablar de una crítica de la legalidad, democratización de la misma, en definitiva, de una amplia deslegitimación de esa legalidad ${ }^{18}$.

Este reclamo de Elías Díaz, dirigido a la superación de la estrecha legitimidad racional-formal (potenciando en parte su fondo crítico y democrático), está finalmente conectado con la crisis de la legitimidad racional moderna, y nos coloca ya ante una nueva dimensión social: la sociedad posindustrial, capitalista avanzada, o, en la terminología más reciente, posmoderna. La sociedad capitalista avanzada -dirá Habermas- se diferencia fundamentalmente de la sociedad capitalista liberal que vivió Marx porque el desarrollo de las fuerzas de producción ha perdido su carácter crítico de ilustración política y se ha convertido en fundamento de legitimación ideológica. En efecto,

no ha resultado incompatible en modo alguno con el reconocimiento de una dimensión de la legitimidad de carácter social» (pág. 29).

${ }^{16}$ Ibídem., págs. 50.

${ }^{17}$ Ibíd., págs. 53-55.

${ }^{18}$ Ibíd., págs. 56-57. 
la intervención del Estado en la economía para corregir y estabilizar las propias tendencias autodestructivas del capital, confirma que este no es capaz de regularse a sí mismo. Al mismo tiempo, este paso del Estado a protector y regulador del funcionamiento económico requiere una nueva legitimación directa ${ }^{19}$.

3. Aunque de menor solera que el concepto de modernidad, también el de posmodernidad ha dado lugar a una abundante literatura ${ }^{20}$. Como en el caso anterior, se pueden enumerar un conjunto de elementos estrechamente vinculados con este fenómeno. Algunos de los más relevantes serían los de fragmentación, desintegración, ambigüedad, incoherencia, malestar, primado del placer, de la voluntad, de los impulsos... Paralelamente, la posmodernidad se presenta acompañada de una lista de defunciones (Dios, el sujeto, la utopía, etc.) que no deja de ser inquietante.

Dejando de lado la cuestión del origen filosófico y estético del posmodernismo (Nietzsche, Heidegger), hay que subrayar que sus diferentes intérpretes han atribuido diversa significación a los elementos antes reseñados. No obstante existen algunos comúnmente admitidos como síntomas característicos. Es el caso de la fragmentación y la dispersión, que implica la desaparición de los tradicionales centros de referencia epistemológicos, éticos o estéticos. Se trata de una nueva relación social, dirá África Vidal, en la que los puntos de vista son múltiples, ofreciendo al observador una pluralidad de interpretaciones discontinuas y fragmentarias. Como consecuencia, las definiciones precisas y dogmáticas dejan paso a un conocimiento siempre inconcluso. La preeminencia de lo desintegrado, dirá por su parte Ballesteros, supone la defensa de la esquizofrenia (así Deleuze, siguiendo a Nietzsche); frente a un lenguaje sometido a la ideología burguesa no cabe el enfrentamiento, sino la fragmentación de las viejas estructuras de la ciencia y la literatura.

En principio, se trata de una situación social que parece incoherente con la característica, antes recogida, de la intervención estatal en las sociedades de capitalismo avanzado, que sugiere unidad, antes que fragmentación. Es este un problema que exige pasar al diagnóstico,

19 J. Habermas, La reconstrucción... cit., pág. 277. También del mismo: Problemas de legitimación en el capitalismo tardio, trad. cast. J. L. Etcheverry, Ed. Amorrortu, Buenos Aires, 1975.

${ }^{20}$ Pueden destacarse: J. Picó (ed.): Modernidad y postmodernidad, Ed. Alianza, 1988; J. Foster, La postmodernidad, Ed. Kairós, Barcelona, 1985; G. Vattimo y otros: En torno a la posmodernidad, Ed. Anthropos, Barcelona, 1990; J. Ballesteros, Postmodernidad: decadencia o resistencia, Ed. Tecnos, Madrid, 1989; C. África Vidal: ¿Qué es el posmodernismo? Publicaciones de la Universidad de Alicante, Alicante, 1989; J. F. Lyotard: La condición posmoderna, Ed. Cátedra, Madrid, 1984. 
y desde este campo, Klappenbach apunta que nos encontramos ante un holismo que no puede identificarse con el determinismo mecánico de la economía, pues aunque ésta siga siendo determinante ya no lo es en una sola dirección, sino que existe una interrelación entre economía, política e ideología. Más bien ocurre que las sociedades occidentales carecen de un centro organizador que asegure unidad y cohesión. Funcionan por un complejo acuerdo en el que se comprometen diversos sectores sociales ${ }^{21}$.

Por su parte, Jameson interpreta esta contradicción en función de lo que entiende como tercera etapa del capitalismo. En efecto, siguiendo a Mandel, identifica tres etapas principales en el desarrollo de la economía capitalista. La primera, representada por el capitalismo mercantil, se correspondería desde el punto de vista tecnológico con la producción mecánica de motores de vapor, y desde el punto de vista cultural con el realismo. La segunda, etapa del capitalismo monopolista e imperialista, se corresponde con la producción de motores eléctricos y de combustión en lo tecnológico, y con el modernismo en lo cultural. Por fin, la etapa posindustrial o multinacional, se manifestaría, tecnológicamente, en la electrónica y en los ingenios nucleares, y culturalmente en el posmodernismo. Pues bien, desde este ángulo, el posmodernismo carece de los elementos de fuerza y velocidad que acompañaron a las viejas máquinas y que causaban admiración. Por el contrario, sus máquinas son más de representación que de producción: ofrecen un esquema privilegiado de representación del poder y del control al que no alcanzamos con nuestro simple entendimiento. La red informática y comunicacional expresa, en definitiva, la nueva red global descentralizada de la nueva fase del sistema mundial del capitalismo multinacional $^{22}$.

Esta noción de la representación que introduce Jameson nos permite pasar a un segundo elemento sintomático, de especial relieve para la legitimación posmoderna. La representación supone la sustitución de la realidad por los signos de la misma. En la medida en que el vertiginoso círculo del consumo termina valiendo por sí mismo, y no por las necesidades objetivas, asistimos a una pérdida de fines, a un vaciamiento de la realidad, a una pérdida de sentido. De la representación pasamos entonces al simulacro, en el que las cosas aparecen representadas por sus dobles, más brillantes y auténticas que el original. A su vez, el simulacro se expresa a través del espectáculo, pues es característica de éste formar un universo autónomo,

${ }^{21}$ A. Klappenbach: Ética y posmodernidad, Ed. I.C.E. de la Universidad de Alcalá de Henares, Alcalá de Henares, Madrid, 1990, págs. 34-35.

${ }^{22}$ F. Jameson: El posmodernismo o la lógica cultural del capitalismo avanzado, trad. cast. J. L. Pardo, Ed. Paidós, Barcelona, 1991, págs. 80-81 y 85. 
cuyas reglas acepta el espectador sin necesidad de referirse a una realidad externa. Este código del espectáculo penetra en los diversos ámbitos de la vida social, como la cultura o la política. Ciertamente, en este último ámbito se ha dado desde antiguo el elemento espectacular, como apoyo a un programa o como forma de persuasión. En la actualidad, sin embargo, se trata más bien de seducir, esto es, de introducir al espectador (seducido) en el propio mundo, en el propio discurso del seductor. Obtenemos así elementos que hacen posible una nueva línea de legitimación posmoderna (aunque, sin duda, con importantes antecedentes históricos), en la medida en que el complejo representación -seducciónespectáculo constituye ya por sí mismo una forma de legitimación. El poder, la cultura, no encuentran, pues, su legitimación en fuentes objetivas (naturaleza, razón, utilidad), sino en sí mismos ${ }^{23}$.

Si pasamos ahora al plano del lenguaje, en el que la posmodernidad ha operado también modificaciones importantes, podremos formar una noción más completa de la legitimación posmoderna, a la que llamaremos, provisionalmente, legitimación performativa.

Con la introducción del lenguaje informático, la ambigüedad propia del lenguaje natural (y también sus posibilidades críticas) es corregida y relegada a un segundo plano. Pues se trata de un lenguaje que encuentra dentro de sí mismo recursos suficientes para solucionar cualquier problema. Si ponemos en contacto esta característica con la anterior línea del espectáculo-seducción, habrá que concluir que en la posmodernidad las reglas del juego son inmanentes al juego mismo, en el sentido de que el lenguaje crea (también) su propio mundo, cuya aceptación es condición para participar en él. De ahí que la tesis de los juegos del lenguaje sea esencialmente posmoderna: no hay reglas que abarquen a todos los juegos y puedan servir de criterio para la crítica. Cada juego lingüístico, pues, incluido el Derecho, posee sus propias reglas, y cualquier legitimación del mismo ha de realizarse a través de la puesta en marcha de sus reglas ${ }^{24}$.

4. Indudablemente, la idea de legitimación performativa ofrece interesantes posibilidades en su aplicación al mundo del Derecho. Probablemente sea Luhmann, con su concepción sistémica del Derecho según la cual el subsistema del ordenamiento jurídico se legitima a sí mismo por su funcionamiento, o sea, en la medida en que es capaz de solucionar los conflictos que se le suscitan, el que ofrezca una versión más ilustrativa de ésta tesis. Sin embargo, puesto

${ }^{23}$ A. Klappenbach, cit., págs. 38, 40 y 41. Cfr. J. Baudrillard, Cultura y simulacro, Ed. Kairós, Barcelona, 1978.

${ }^{24}$ Ibídem, pág. 44. 
que la posición de Luhmann es conocida ${ }^{25}$, me conformaría con dejar constancia de este extremo, para centrarme en el examen, siquiera sea de modo puramente indicativo, de otras posibilidades de aplicación de la legitimación posmoderna en el campo del Derecho. Especialmente las que conectan con los juegos del lenguaje, en este caso, jurídico.

Es un hecho sobradamente conocido que la crisis del Estado capitalista, y el correspondiente paso al Estado posindustrial y, en general, a la posmodernidad, ha repercutido, sobre todo en el sistema de fuentes del Derecho. El aumento de la legislación llamada material o especial, sobre la formal, ha dado lugar a fenómenos todavía hoy discutidos entre los juristas. En este sentido, se habla de «deslegificación», «desregulación», «descodificación» ${ }^{26}$. De entre todos estos cambios en las fuentes del Derecho, quisiera destacar uno sobre todo: la aparición del Derecho judicial, esto es, la atribución a los jueces de un poder creador de Derecho.

Se trata de una cuestión largamente debatida, y no es mi propósito entrar en dicha polémica, sino más bien subrayar que independientemente de dicha creatividad, y de los límites de la misma, es lo cierto que los procedimientos seguidos por los aplicadores del Derecho en el cometido de su función han cambiado sustantivamente, en especial en lo que se refiere a sus instrumentos discursivos y a las justificaciones de sus decisiones. Es esta, precisamente la circunstancia que explica el renovado interés que hoy despiertan los temas de interpretación y argumentación judicial ${ }^{27}$.

Quienes estén acostumbrados a ver en Kelsen un rígido formalista tal vez se sorprendan por el hecho de situar a este autor en el origen de estos cambios. Una ojeada a su teoría de la interpretación y a su tesis del carácter constitutivo de la sentencia judicial será suficiente para confirmar que no se trata de una situación precipitada ${ }^{28}$.

${ }^{25}$ Cfr. entre la abundante literatura de Luhmann: Fin y racionalidad en los sistemas, trad. cast. J. Nicolás. Editora Nacional, Madrid, 1983, en especial págs. 153 y ss. Entre la también abundante literatura sobre Luhmann destacaría el trabajo de Ingeborg Mauss: «Sobre la relación actual entre ideología y realidad social: el ejemplo de la teoría del derecho en la República Federal de Alemania», en Anales de la Cátedra Francisco Suárez, no 17, 1977, págs. 265 y ss.

${ }^{26}$ Cfr. V. Italia, La delegificazione, Ed.Giuffré, Milano, 1992; J. E. Soriano, Desregulación, y privatización del Derecho administrativo, Publicaciones del Real Colegio de España, Bolonia, 1993; N. Irti: La edad de la descodificación, Trad. cast. L. Rojo, Ed. José Ma Bosch, Barcelona, 1991.

${ }^{27}$ M. Atienza, Tras la justicia. Una introducción al Derecho y al razonamiento jurídico, Ed. Ariel, Barcelona, 1993.

${ }^{28}$ H. Kelsen, Teoría General del Derecho y del Estado, trad. cast. E. García Maynez, Ed. U.N.A.M., México, 1988, pp. 159-161; Id.: Teoría pura del Derecho (ed. original de 1960), trad. cast. R. J. Vernengo, Ed. U.N.A.M., México, 1979, págs. 51-52. 
En efecto, Kelsen lleva a cabo un explícito reconocimiento de la existencia de elementos volitivos en la construcción de la sentencia judicial. En posteriores desarrollos de esta línea, diferentes autores subrayarán cada vez más la importancia de dichos elementos, hasta llegar a romper el marco normativo y semántico (Hart) en el que se insertaban y hacían posible una legitimación, hasta cierto punto externa, de la decisión. Aparece como consecuencia una argumentación judicial que encuentra su racionalidad dentro de sí misma, en cuanto lenguaje dotado de sus propias reglas, volcado, encerrado, en ellas.

Se trata de una forma de legitimación típicamente posmoderna (performativa), en la que se combina la flexibilidad con la tecnicidad, la socialidad con la autorreferencia. Indudablemente, contiene también importantes elementos comunicativos, que, sin embargo, no autorizan su confusión con una legitimación comunicacional como la propuesta por Habermas, más bien situada, en mi opinión, en el campo de la modernidad y no en el de la posmodernidad. Por el contrario, esta línea de legitimación pone de relieve el riesgo que anida en la acción comunicativa misma, es decir, el riesgo de que los elementos críticos que aseguran la racionalidad de la comunicación (y sus resultados) no estén, a su vez, suficientemente asegurados, dando entrada a una fragmentación que sólo es posible recomponer en el interior de un particular juego lingüístico autolegitimante y carente de referencias objetivas ${ }^{29}$. Es el caso de la figura del «juez como solucionador de conflictos» que propone la neoretórica, como un paso más allá del juez realista, en la medida en que la decisión no encuentra su marco justificativo en elementos (externos) de justicia social, sino que, perdida esta referencia, sólo puede encontrar su razonabilidad en lo opinable, lo que dota a la misma de una considerable carga relativista (cuando no demagógica) ${ }^{30}$.

Los esfuerzos de un jurista como Joseph Esser, situado en una posición alejada de la anterior, para garantizar la racionalidad de la decisión desde la comunicación y el consenso son, a este respecto, ilustrativos. Racionalidad de la decisión judicial significa aquí producción de un consenso relativo a la oportunidad y justicia de una de las diversas posibilidades de solución. Se trata, pues, de una razonabilidad fundada en la aceptación social de la decisión, un control intersubjetivo que en una sociedad fragmentada corre el constante

${ }^{29}$ Así, sostendrá Lyotard, ob. cit., págs. 73, que el consenso no es tanto la finalidad del diálogo cuanto un estadio del mismo, cuyo fin es, precisamente, la búsqueda de la diferencia.

${ }^{30}$ Ch. Perelmann: La lógica jurídica y la nueva retórica, trad. cast. L. Díez Picazo, Ed. Civitas, Madrid, 1979, págs. 177 y ss. 
riesgo de expresar más bien una relativización de valores. La referencia a un público, finalmente, que, dejando aparte la posibilidad de que sea manipulado, puede manifestar concepciones irracionales (al no existir una regla universal de racionalidad que no sea la del desarrollo económico poscapitalista $)^{31}$.

He tratado de localizar, en conclusión, una parte (simplemente) de la problemática que suscita la legitimación posmoderna, con especial referencia al campo del Derecho. No puedo concluir, sin embargo, sin dejar de apuntar que sería un error responder a los riesgos y dificultades que empañan los aspectos democráticos que sin duda contiene esta forma de legitimación (como el reclamo del diálogo, de la comunicación, la incorporación y reconocimiento de la diferencia) con una propuesta que pretenda la reinstauración de un sistema objetivo de valores, recuperando así, con más o menos variantes, una línea de justificación iusnaturalista ${ }^{32}$. Creo que, puestos a optar por una salida de la posmodernidad es más aceptable la propuesta de Orestano, que antes de lamentarse por la pérdida de un mundo de «esencias», manifiesta una (fundada) confianza en el carácter operacional de los conceptos que pueden crearse a la medida de las necesidades que nos apremian ${ }^{33}$.

${ }^{31}$ J. Esser: Vorverständnis und Methodenwahl in der Rechtsfindung, Frankfurt, 1972: He utilizado la traducción italiana de S. Patti y G. Zaccaria: Precomprensione e scelta del metodo nel proceso di individuazione del diritto, Ed. Scientifiche Italiane, Napoli, 1983, pp. 21-22 y 140-151. Importante G. Zaccaria: «L'objettivitá del giudize tra esegesi normativa e politica del diritto», en Rivista de diritto civile, 1979, págs. 603 y ss.

${ }^{32}$ F. D'Agostino, «La giustizia tra moderno e postmoderno», cap. VIII de su Filosofia del Diritto, Ed. Giappichelli, Torino, 1993, págs. 111 y ss.

${ }^{33}$ R. Orestano, «Del 'post-moderno', de la 'scientia iuris' e di altro» en, del mismo autor: Edificazione del giuridico, Ed. Il Mulino, Bologna, 1989, pág. 335. 